
\title{
$\begin{array}{ll}\text { Research Square } & \begin{array}{l}\text { Preprints are preliminary reports that have not undergone peer review. } \\ \text { They should not be considered conclusive, used to inform clinical practice, } \\ \text { or referenced by the media as validated information. }\end{array}\end{array}$ \\ Determination of genetic effects and functional SNPs of bovine HTR1B gene on milk fatty acid traits
}

\section{Mingyue Cao}

China Agricultural University

\section{Lijun Shi}

China Agricultural University

\section{Peng Peng}

China Agricultural University

\section{Bo Han}

China Agricultural University

Lin Liu

Beijing Dairy Cattle Center

Xiaoqing Lv

Beijing Dairy Cattle Center

\section{Zhu Ma}

Beijing Dairy Cattle Center

Shengli Zhang ( $\sim$ zhangslcau@cau.edu.cn )

China Agricultural University https://orcid.org/0000-0002-9001-6000

Dongxiao Sun

China Agricultural University

\section{Research article}

Keywords: Genetic effects, HTR1B, Milk fatty acids, Dairy cattle, Luciferase assay

Posted Date: December 2nd, 2020

DOI: https://doi.org/10.21203/rs.3.rs-118948/v1

License: (c) (1) This work is licensed under a Creative Commons Attribution 4.0 International License. Read Full License 


\section{Abstract}

Background: Our previous genome-wide association study (GWAS) on milk fatty acid traits in Chinese Holstein cows revealed, the SNP, BTB-01556197, was significantly associated with C10:0 at genome-wide level $(P=0.0239)$. It was located in the down-stream of 5-hydroxytryptamine receptor 1B (HTR1B) gene that has been shown to play an important role in the regulation of fatty acid oxidation. Hence, we considered it as a promising candidate gene for milk fatty acids in dairy cattle. In this study, we aimed to investigate whether the HTR1B gene had significant genetic effects on milk fatty acid traits.

Results: We re-sequenced the entire coding region and 3,000 bp of $5^{\prime}$ and 3 ' flanking regions of HTR1B gene. A total of 13 SNPs was identified, containing one in $5^{\prime}$ flanking region, two in $5^{\prime}$ untranslated region (UTR), two in exon 1, five in 3' UTR, and three in 3' flanking region. By performing genotype-phenotype association analysis with SAS9.2 software, we observed that 13 SNPs were significantly associated with medium-chain saturated fatty acids such as C6:0, C8:0 and C10:0 ( $P<0.0001 \sim 0.042)$. With Haploview 4.1 software, linkage disequilibrium (LD) analysis was performed that two haplotype blocks formed by two and ten SNPs were observed. Haplotype-based association analysis indicated that both haplotype blocks were strongly associated with C6:0, C8:0 and C10:0 as well $(P<0.0001$ $\sim 0.0071$ ). With regards to the missense mutation in exon 1 (g.17303383G $>\mathrm{T}$ ) that reduced amino acid change from alanine to serine, we predicted that it altered the secondary structure of HTR1B protein with SOPMA. In addition, we predicted that three SNPs in promoter region, g.17307103A $>$ T, g.17305206T $>$ G and g.17303761C>T, altered the binding sites of transcription factors (TFs) HMX2, PAX2, FOXP1ES, MIZ1, CUX2, DREAM, and PPAR-RXR by Genomatix. Of them, luciferase assay experiment further confirmed that the allele $T$ of g.17307103A>T significantly increased the transcriptional activity of $H T R 1 B$ gene than allele $\mathrm{A}(P=0.0007)$.

Conclusions: In conclusion, our findings provided first evidence that the HTR1B gene had significant genetic effects on milk fatty acids in dairy cattle.

\section{Background}

Milk fat, a vital nutritional ingredient of milk, is considered as one of the economic traits of milk production in dairy cattle [1]. Triglyceride synthesized by fatty acids and a-glycerophosphate in mammary epithelial cells is the main component of milk fat [2]. Fatty acids contain saturated fatty acids (SFAs) and unsaturated fatty acids (UFAs). SFAs are related to the increased cholesterol lever and risk of cardiovascular diseases [3,4], while UFAs are beneficial for reducing the risk of heart and other diseases $[5,6]$. Many previous studies have shown that the phenotypic variation of milk fatty acid compositions were genetically controlled and the heritability estimates were around $0.14 \sim 0.33$ for SFAs and $0.08 \sim 0.29$ for UFAs in Holstein cattle [7-11].

One of genome-wide significant SNPs, BTB-01556197 associated with C10:0 $(P=0.0239)$ identified in previous GWAS [12], was located in the down-stream of 5-hydroxytryptamine receptor 1B (HTR1B) gene. The bovine HTR1B gene has merely one exon spanning 4,305 bp and was involved in the c-AMP signaling pathway that was related to PI3K-Akt pathway, a well-known pathway for fat synthesis and metabolism [13]. Hence, we considered the HTR1B gene as a promising candidate for milk fatty acid traits in dairy cattle. In the present study, we aimed to further preform association analysis in a different Chinese Holstein population to confirm the genetic effects of HTR1B on milk fatty acids and to identify potential functional genetic variations.

\section{Results}




\section{SNPs identification}

A total of 13 SNPs (Table 1) was identified, including one (g.17307103A $>\mathrm{T}$ ) in $5^{\prime}$ flanking region, two (g.17305206T $>\mathrm{G}$ and g.17303761C $>\mathrm{T}$ ) in $5^{\prime}$ untranslated region (UTR), two (g.17303383G $>\mathrm{T}$ and g.17303042C $>\mathrm{G}$ ) in the exon 1, five (g.17302291 C > G, g.17302078G > T, g.17301689T > C, g.17301647G > T and g.17299803A > G) in 3' UTR, and three (g.17298882A > G, g.17296725C > T and g.17296695T > C) in $3^{\prime}$ flanking region. Of note, g.17303383G $>T$ in exon 1 was a missense mutation resulting in an amino acid replacement from alanine (GCC) to serine (TCC). The detailed information, and genotypic and allele frequencies of the 13 SNPs were shown in Table 1. 
Table 1

Detailed information of 13 SNPs identified in HTR1B gene

\begin{tabular}{|c|c|c|c|c|c|c|c|c|}
\hline SNP name & Location & $\begin{array}{l}\text { Position } \\
\text { (UMD } \\
3.1 .1 \text { ) }\end{array}$ & GenBank no. & Genotype & NO. & Frequency & Allele & Frequency \\
\hline \multirow{3}{*}{$\begin{array}{l}\text { g. } 17307103 \mathrm{~A} \\
>\mathrm{T}\end{array}$} & \multirow{3}{*}{$\begin{array}{l}5^{\prime} \\
\text { flanking } \\
\text { region }\end{array}$} & \multirow{3}{*}{$\begin{array}{l}\text { Chr9: } \\
17307103\end{array}$} & \multirow[t]{3}{*}{ rs207969357 } & AA & 481 & 0.4621 & $A$ & 0.6830 \\
\hline & & & & $\mathrm{TT}$ & 100 & 0.0961 & $\mathrm{~T}$ & 0.3170 \\
\hline & & & & TA & 460 & 0.4419 & & \\
\hline \multirow{3}{*}{$\begin{array}{l}\text { g. } 17305206 \mathrm{~T} \\
>\mathrm{G}\end{array}$} & \multirow[t]{3}{*}{ 5' UTR } & \multirow{3}{*}{$\begin{array}{l}\text { Chr9: } \\
17305206\end{array}$} & \multirow[t]{3}{*}{ rs476055046 } & $\mathrm{TT}$ & 651 & 0.6242 & $\mathrm{~T}$ & 0.8121 \\
\hline & & & & GG & 0 & 0.0000 & G & 0.1879 \\
\hline & & & & GT & 392 & 0.3758 & & \\
\hline \multirow{3}{*}{$\begin{array}{l}\text { g. } 17303761 \mathrm{C} \\
>\mathrm{T}\end{array}$} & \multirow[t]{3}{*}{ 5' UTR } & \multirow{3}{*}{$\begin{array}{l}\text { Chr9: } \\
17303761\end{array}$} & \multirow[t]{3}{*}{ rs133683693 } & $\mathrm{CC}$ & 113 & 0.1088 & $\mathrm{C}$ & 0.3503 \\
\hline & & & & $\mathrm{TT}$ & 424 & 0.4081 & $\mathrm{~T}$ & 0.6497 \\
\hline & & & & $\mathrm{CT}$ & 502 & 0.4832 & & \\
\hline \multirow{3}{*}{$\begin{array}{l}\text { g. } 17303383 G \\
>T\end{array}$} & \multirow[t]{3}{*}{ Exon-1 } & \multirow{3}{*}{$\begin{array}{l}\text { Chr9: } \\
17303383\end{array}$} & \multirow[t]{3}{*}{ rs209984404 } & GG & 504 & 0.4846 & G & 0.6986 \\
\hline & & & & TT & 91 & 0.0875 & $\mathrm{~T}$ & 0.3014 \\
\hline & & & & GT & 445 & 0.4279 & & \\
\hline \multirow{3}{*}{$\underset{>G}{g .17303042 C}$} & \multirow[t]{3}{*}{ Exon-1 } & \multirow{3}{*}{$\begin{array}{l}\text { Chr9: } \\
17303042\end{array}$} & \multirow[t]{3}{*}{ rs208945882 } & $\mathrm{CC}$ & 499 & 0.4897 & $\mathrm{C}$ & 0.6977 \\
\hline & & & & GG & 96 & 0.0942 & G & 0.3023 \\
\hline & & & & CG & 424 & 0.4161 & & \\
\hline \multirow{3}{*}{$\begin{array}{l}\text { g. } 17302291 C \\
>G\end{array}$} & \multirow[t]{3}{*}{ 3' UTR } & \multirow{3}{*}{$\begin{array}{l}\text { Chr9: } \\
17302291\end{array}$} & \multirow[t]{3}{*}{ rs136136524 } & $\mathrm{CC}$ & 279 & 0.2680 & $\mathrm{C}$ & 0.5259 \\
\hline & & & & GG & 225 & 0.2161 & $G$ & 0.4741 \\
\hline & & & & CG & 537 & 0.5159 & & \\
\hline \multirow{3}{*}{$\begin{array}{l}\text { g. } 17302078 G \\
>T\end{array}$} & \multirow[t]{3}{*}{ 3' UTR } & \multirow{3}{*}{$\begin{array}{l}\text { Chr9: } \\
\text { 17302078 }\end{array}$} & \multirow[t]{3}{*}{ rs135063494 } & GG & 502 & 0.4818 & $\mathrm{G}$ & 0.6972 \\
\hline & & & & $\mathrm{TT}$ & 91 & 0.0873 & $\mathrm{~T}$ & 0.3028 \\
\hline & & & & GT & 449 & 0.4309 & & \\
\hline \multirow{3}{*}{$\begin{array}{l}\text { g. } 17301689 \mathrm{~T} \\
>\mathrm{C}\end{array}$} & \multirow[t]{3}{*}{ 3' UTR } & Chr9: & rs379078023 & $\mathrm{CC}$ & 103 & 0.1012 & $\mathrm{C}$ & 0.3089 \\
\hline & & & & $\mathrm{TT}$ & 492 & 0.4833 & $\mathrm{~T}$ & 0.6911 \\
\hline & & & & CT & 423 & 0.4155 & & \\
\hline g.17301647G & 3' UTR & Chr9: & rs109548495 & $\mathrm{GG}$ & 115 & 0.1103 & G & 0.3514 \\
\hline & & & & $\mathrm{TT}$ & 425 & 0.4075 & $\mathrm{~T}$ & 0.6486 \\
\hline & & & & GT & 503 & 0.4823 & & \\
\hline $\begin{array}{l}\text { g. } 17299803 A \\
>\text { G }\end{array}$ & 3' UTR & $\begin{array}{l}\text { Chr9: } \\
17299803\end{array}$ & rs208790360 & $\mathrm{AA}$ & 499 & 0.4854 & $A$ & 0.6989 \\
\hline
\end{tabular}




\begin{tabular}{|c|c|c|c|c|c|c|c|c|}
\hline SNP name & Location & $\begin{array}{l}\text { Position } \\
\text { (UMD } \\
\text { 3.1.1) }\end{array}$ & GenBank no. & Genotype & No. & Frequency & Allele & Frequency \\
\hline & & & & GG & 90 & 0.0875 & G & 0.3011 \\
\hline & & & & AG & 439 & 0.4270 & & \\
\hline \multirow{3}{*}{$\begin{array}{l}\text { g. } 17298882 A \\
>G\end{array}$} & \multirow{3}{*}{$\begin{array}{l}3^{\prime} \\
\text { flanking } \\
\text { region }\end{array}$} & \multirow{3}{*}{$\begin{array}{l}\text { Chr9: } \\
17298882\end{array}$} & \multirow[t]{3}{*}{ rs380460000 } & AA & 2 & 0.0038 & A & 0.5019 \\
\hline & & & & GG & 0 & 0.0000 & G & 0.4981 \\
\hline & & & & AG & 523 & 0.9962 & & \\
\hline \multirow{3}{*}{$\begin{array}{l}\text { g. } 17296725 \mathrm{C} \\
>\mathrm{T}\end{array}$} & \multirow{3}{*}{$\begin{array}{l}3^{\prime} \\
\text { flanking } \\
\text { region }\end{array}$} & \multirow{3}{*}{$\begin{array}{l}\text { Chr9: } \\
17296725\end{array}$} & \multirow[t]{3}{*}{ rs208087947 } & $\mathrm{CC}$ & 503 & 0.4846 & C & 0.6985 \\
\hline & & & & TT & 91 & 0.0877 & $\mathrm{~T}$ & 0.3015 \\
\hline & & & & CT & 444 & 0.4277 & & \\
\hline \multirow{3}{*}{$\begin{array}{l}\text { g. } 17296695 \mathrm{~T} \\
>C\end{array}$} & \multirow{3}{*}{$\begin{array}{l}3^{\prime} \\
\text { flanking } \\
\text { region }\end{array}$} & \multirow{3}{*}{$\begin{array}{l}\text { Chr9: } \\
17296695\end{array}$} & \multirow[t]{3}{*}{ rs133617481 } & $\mathrm{CC}$ & 90 & 0.0872 & C & 0.2994 \\
\hline & & & & TT & 504 & 0.4884 & $\mathrm{~T}$ & 0.7006 \\
\hline & & & & CT & 438 & 0.4244 & & \\
\hline
\end{tabular}

\section{Associations between the SNPs with 24 milk fatty acids}

By performing association analysis on the SNPs with 24 kinds of milk fatty acids with SAS9.2, significant genetic associations were observed (Additional file 1: Table S1). The SNP, g.17307103A $>$ T, was significantly associated with C6:0, C8:0, C10:0, C16:1, C16 index and C17 index $(P=0.0003 \sim 0.042)$. Both g.17305206T > G and g.17303761C > T were significantly associated with C6:0, C10:0, C12:0, C14:0, C18:1cis-9, C18index, SFA, UFA, SFA/UFA and total index $(P<0.0001 \sim 0.036)$, and they were significantly associated with three (C8:0, C16:1 and C20:0; $P<0.0001 \sim 0.0213)$ and two (C17:0, $P=0.0358$; and C17index, $P=0.0148)$ milk fatty acid traits, respectively. Six SNPs were significantly associated with seven milk fatty acid traits, namely, g.17303383G > T (C6:0, C8:0, C10:0, C14:0, C16:1, C16index, and C17index; $P=0.0003 \sim 0.0145)$, g.17303042C > G (C8:0, C10:0, C14:0, C16:1, C17:0, C16index, and C17index; $P<$ $0.0001 \sim 0.0286)$, g.17302291C > G (C6:0, C8:0, C10:0, C17:0, SFA, SFA/UFA and total index; $P=0.0005 \sim 0.0387)$, g.17302078G > T (C6:0, C8:0, C10:0, C14:0, C16:1, C16 index and C17 index; $P<0.0001 \sim 0.0277)$, g.17299803A > G (C6:0, C8:0, C10:0, C14:0, C16:1, C16index and C17index; $P=0.001 \sim 0.0305)$, and g.17296725C > T (C6:0, C8:0, C10:0, C14:0, C16:1, C16index and C17index; $P<0.0001 \sim 0.0122)$. The g.17301689T $>C$ showed strong associations with C6:0, C8:0, C10:0, 16:1, C16 index and C17index $(P=0.0002 \sim 0.0204)$. The g.17301647G $>$ T, showed strong associations with C6:0, C10:0, C12:0, C14:0, C17:0, C18:1cis-9, C17 index, SFA, UFA, SFA/UFA and total index $(P<$ $0.0001 \sim 0.0445)$. The g.17298882A $>\mathrm{G}$ was significantly associated with C14:0, C17:0, C17:1, C18:1 cis-9, C20:0, SFA, UFA, SFA/UFA and total index $(P<0.0001 \sim 0.049)$. The g.17296695T $>C$ was significantly associated with $\mathrm{C6}: 0$, C8:0, 10:0, C14:0, C16:1, C17:0, C16 index and C17 index $(P<0.0001 \sim 0.0492)$. While no significant association was observed for C11:0, C13:0, C14:1, C15:0, C16:0, C18:0 and C14 index $(P>0.05)$.

Correspondingly, the additive (a), dominance (d), and allele substitution () effects of the identified SNPs were calculated (Additional file 2: Table S2), and the results showed that 11 SNPs had strong genetic effects on C6:0, C8:0, 
C10:0, C12:0, C14:0, C16:1, C17:0, C18:0, C18:1cis-9, C18index, C20:0, C16index, C17index, SFA, UFA, SFA/UFA, and total index $(P<0.05)$.

\section{Associations between the haplotype blocks with 24 milk fatty acid traits}

Among the 13 SNPs identified in this study, two haplotype blocks were observed with the Haploview 4.1 software (Fig. 1). The block 1, formed by g.17296725C > T and g.17296695T > C, had two kinds of haplotypes $(\mathrm{H} 1=\mathrm{TC}$ and $\mathrm{H} 2=\mathrm{CT}$ ) with the frequencies of $69.6 \%$ and $30.4 \%$, respectively. The block 2 was composed of ten SNPs,

g.17307103A> T, g.17305206T > G, g.17303761C > T, g.17303383G > T, g.17303042C > G, g.17302291C>G, g.17302078G > T, g.17301689T > C, g.17301647G $>$ T and g.17299803A $>$ G, and had seven haplotypes $(\mathrm{H} 1=$ AGTGCCGCTA, 34.5\%; H2 = GTCTGGTTTT, 30.3\%; H3 = ATTGGCGTGA, 13.8\%; H4 = ATTGCCGTTA, $12.9 \%$; H5 = ATTGCCGTGA, 4.4\%; H6 = ATTGGCGTTA, 1.6\%; and H7 = ATTGGCGTTT, 1.5\%).

Subsequently, we performed haplotype-based association analysis with SAS9.2, and found that the haplotype block1 and block2 were significantly associated with nine (C6:0, C8:0, C10:0, C14:0, C16:1, 17:0, C20:0, C16index and C17index; $P=0.0002 \sim 0.0476)$ and six (C6:0, C8:0, C10:0, C20:0, C17index and total index; $P<0.0001 \sim 0.0265)$ milk fatty acids, respectively (Additional file 3 : Table S3). While, none of significant associations were detected with $\mathrm{C} 11: 0$, C12:0, C13:0, C14:1, C15:0, C16:0, 17:1, C18:0, C18:1cis-9, C18index, C14index, SFA, UFA and SFA/UFA $(P>0.05)$.

Changes of the HTR1B protein secondary structure and function caused by the missense mutation $\mathrm{g} .17303383 \mathrm{G}>\mathrm{T}$

Using SOPMA software, we predicted that the missense mutation in exon 1, g.17303383G > T, changed the HTR1B protein secondary structure, including a-helix (46.90-41.44\%), extended strand (13.40-16.38\%), $\beta$-turn (2.48-1.74\%), and random coil (37.22-40.45\%) with the allele from $\mathrm{G}$ to T. While, the HTR1B protein function was not altered by the missense mutation with the scores 0.25 (SIFT) and - 1.42 (PROVEAN).

\section{Changes of transcriptional activity caused by g.17307103A $>$ T, g.17305206T $>$ G and g.17303761C $>$ T}

By searching the TFBSs of the three SNPs in 5' UTR and flanking regions with Genomatix, we discovered that the allele T of g.17307103A > T created two TFBSs for HMX2 (Hmx2/Nkx5-2 homeodomain transcription factor) and PAX2 (Zebrafish PAX2 paired domain protein), and the allele $\mathrm{G}$ of g.17305206T > G created a TFBS for FOXP1ES (Alternative splicing variant of FOXP1, activated in ESCs). For g.17303761C > T, the allele C created two TFBSs for MIZ1 (Myc-interacting Zn finger protein 1, zinc finger and BTB domain containing 17) and CUX2 (Cut-like homeobox 2, dimeric binding site), and the allele T created two TFBSs for DREAM (Downstream regulatory element-antagonist modulator, Ca2+-binding protein of the neuronal calcium sensors family that binds DRE sites as a tetramer) and PPAR-RXR (PPAR/RXR heterodimers, DR1 sites). The detailed results were shown in Table 2. 
Table 2

Changes of transcription factor binding sites (TFBSs) caused by the SNPs in the $5^{\prime}$ UTR and flanking region of HTR1B

\begin{tabular}{|c|c|c|c|}
\hline SNP & Sequence & TF & Full name \\
\hline \multirow{3}{*}{$\begin{array}{l}\text { g. } 17307103 \mathrm{~A} \\
>\mathrm{T}\end{array}$} & \multicolumn{3}{|l|}{ CCCCAACGCGATTCCCTCCTT } \\
\hline & \multirow[t]{2}{*}{ CCCCAACGCGTTTCCСTCCTT } & $\mathrm{HMX} 2$ & $\begin{array}{l}\mathrm{Hm} \times 2 / \mathrm{Nkx} 5-2 \text { homeodomain transcription } \\
\text { factor }\end{array}$ \\
\hline & & PAX2 & Zebrafish PAX2 paired domain protein \\
\hline \multirow{2}{*}{$\begin{array}{l}\text { g. } 17305206 T \\
>G\end{array}$} & \multicolumn{3}{|l|}{ TTTTGAAGTTTTTTTTTTTTTT } \\
\hline & TTTTGAAGTTTGTTTTTTTTTT & FOXP1ES & $\begin{array}{l}\text { Alternative splicing variant of FOXP1, activated } \\
\text { in ESCs }\end{array}$ \\
\hline \multirow[t]{4}{*}{$\underset{>T}{g .17303761 C}$} & \multirow[t]{2}{*}{ ACCTCGCCCTCGACCTCTCGC } & MIZ1 & $\begin{array}{l}\text { Myc-interacting Zn finger protein 1, zinc finger } \\
\text { and BTB domain containing } 17 \text { (ZBTB17) }\end{array}$ \\
\hline & & CUX2 & Cut-like homeobox 2 , dimeric binding site \\
\hline & \multirow[t]{2}{*}{ ACCTCGCCCTTGACCTCTCGC } & DREAM & $\begin{array}{l}\text { Downstream regulatory element-antagonist } \\
\text { modulator, Ca2+-binding protein of the } \\
\text { neuronal calcium sensors family that binds } \\
\text { DRE (downstream regulatory element) sites as } \\
\text { a tetramer }\end{array}$ \\
\hline & & $\begin{array}{l}\text { PPAR- } \\
\text { RXR }\end{array}$ & PPAR/RXR heterodimers, DR1 sites \\
\hline
\end{tabular}

Further, we utilized the luciferase assay (Fig. 2) to confirm the above prediction results. The luciferase activities of the construct T of g.17307103A > T was observed significantly higher than those of the blank control $(P<0.0001)$, the empty vector PGL4.14 ( $P=0.0022)$, and the construct A $(P=0.0007)$, indicating that the allele T of g.17307103A $>T$ increased the transcriptional activity of HTR1B compared with allele A. However, the luciferase activities of four constructs ( $T$ and $G$ of g.17305206T $>G$, and $C$ and $T$ of g.17303761C $>T$ ) were not strongly changed than those of the blank and empty vector, implying that g.17305206T > G and g.17303761 C > T did not significantly alter the transcriptional activity of $H T R 1 B$ gene.

\section{Discussion}

According to our previous GWAS results and biological functions, the HTR1B gene has been identified as one of novel promising candidates for milk fatty acids in dairy cattle [12]. In the present study, we firstly confirmed that the HTR1B gene showed significant genetic effects on medium-chain saturated fatty acids, implying the regulatory function of HTRTB on formation of milk fatty acid traits in dairy cattle.

As the essential material of constituting the organism, the protein has important biological functions that are largely dependent on its structure. The protein structure defines the biological function [14]. Previous studies reported that protein secondary structure could be used to build safe starting cores to generate the complete protein fold [15], and to set structural constraints for protein threading $[16,17]$. Researching the relation between sequence and structure in protein has the great scientific interest [18], and we can use the sequences to explore the protein evolution and 
function $[19,20]$. Studies reported that the missense mutations caused by the sequence variations were related to the protein function to account for the phenotype variations [21-24]. Here, we identified a missense mutation (g.17303383G > T), and it changed the protein secondary structure by prediction with the SOPMA. While we used SIFT and PROVEAN softwares to detect that the missense mutation did not alter the HTR1B protein function. Hence, the significant associations of g.17303383G > T with milk fatty acids might be due to the LD with the true causal mutations.

Regulatory region, including promoter, enhancer, silencer, and insulator etc [25], are important for the gene regulation and expression [26]. Transcription factors (TFs) are the sequence-specific DNA-binding proteins that regulate gene expression in all organisms [27, 28], and approximately $10 \%$ are implicated in diverse diseases in human [29]. In eukaryotes, multiple TFs cooperatively bind regulatory DNA to temporally and spatially control gene expression [30]. In this study, we predicted that three SNPs (g.17307103A $>$ T, g.17305206T $>\mathrm{G}$ and g.17303761C $>\mathrm{T}$ ) changed the TFBSs. While only g.17307103A > T actually changed the transcriptional activity of HTR1B gene. The allele T of g.17307103A > T was predicted to create two TFBSs for HMX2 and PAX2. The $h m x$ homeobox-containing TF gene family, containing contains $h m x 2$ [31], is highly conserved across species [32-35]. HMX2 is involved in a feedback loop of EGF signaling and located in upstream of the PAX5 of the utricular maculae to affect the inner ear development in zebrafish $[36,37]$. The pax gene family encodes DNA binding TFs that control vital steps in embryonic development and differentiation of specific cell lineages in human [38]. PAX2 as a TF can promote the expression of $A D A M 10$ to negatively regulate the epithelia to mesenchyme transition in human [39]. According to the significant associations and transcriptional activity caused by g.17307103A $>$ T, we suggested that g. $17307103 \mathrm{~A}>\mathrm{T}$ might be a potential causal mutation regulating the HTR1B gene expression by altering the binding sits for the TFs HMX2 and PAX2 to impact the milk fatty acid traits in dairy cattle.

\section{Conclusions}

In this study, we confirmed the significant genetic effects of HTR1B on milk fatty acids using post-GWAS strategy, and identified a potential causal mutation, g.17307103A > T, that altered the transcriptional activity of HTR1B by changing TFBSs for TFs of HMX2 and PAX2. Our findings could be used as valuable molecular information for genetic improvement programs in dairy cattle.

\section{Methods}

\section{Animals and phenotypic data}

A total of 1,065 Chinese Holstein cows from44 sire families was used in this study which were detailed described by Shi et al. [40]. We collected milk samples of these 1,065 cows to measure milk fatty acids in the laboratory of Beijing Dairy Cattle Center (www.bdcc.com.cn). By gas chromatograph, the contents of 16 kinds of main milk fatty acids were directly detected, including SFA: C6:0, C8:0, C10:0, C11:0, C12:0, C13:0, C14:0, C15:0, C16:0, C17:0, C18:0, C20:0; and UFA: C14:1, C16:1, C17:1 and C18:1 cis-9. Based on these phenotype values, we obtained five index traits (C14index, C16index, C17index, C18index, and total index) calculated with the formulas:

$\frac{\text { cis-9 unsaturated }}{\text { cis }-9 \text { unsaturated }+ \text { saturated }} * 100[41]$.

and summarized the SFA, UFA, SFA/UFA. 


\section{SNP identification and genotyping}

We extracted genomic DNA from the blood samples of 1,065 cows and the semen samples of 44 sires using TIANamp Blood DNA Kit (Tiangen, Beijing, China) and salt-out procedure, respectively. DNA quantity and quality were measured by NanoDrop ${ }^{T M}$ ND-2000 Spectrophotometer (Thermo Scientific, Hudson, DE, USA) and $2.0 \%$ agarose gel electrophoresis.

A total of 15 pairs of primers (Additional file 4: Table S4) were designed using the Primer 3.0 (http://primer3.wi.mit.edu/) based on the sequences of all the exons, and 3,000 bp of 5' and 3' flanking regions of the bovine HTR1B gene (Gene ID: 317707), and were synthesized in the Beijing Genomics Institute (Beijing, China). Two DNA pools' construction and polymerase chain reaction (PCR) procedure used the same method as those in our previous study [40]. By sequencing PCR products, we identified potential polymorphic sites and further genotyped identified SNPs in 1,065 cows by matrix-assisted laser desorption/ionization time of flight mass spectrometry (MALDI-TOF MS, Sequenom MassARRAY, Bioyong Technologies Inc. HK).

\section{Statistical analysis}

First, we used the Haploview 4.1 software (Broad Institute of MIT and Harvard, Cambridge, MA, USA) to identify the LD extent among the identified SNPs of the HTR1B gene.

Subsequently, we performed single SNP-based and haplotype-based association analysis. We traced the pedigrees of the 1,065 Chinese Holstein cows back to three generations, as a result, a total of 3,335 individuals were included for association analysis, which kinship matrix (A-matrix) were constructed with SAS9.2 (SAS Institute, Cary, NC, USA). Then, associations between the identified SNPs and haplotype blocks with 24 milk fatty acid traits were performed by SAS9.2 on the basis of the following mixed animal model:

$$
Y_{i j k l m}=\mu+G_{i}+h_{j}+l_{k}+a_{l}+\mathrm{b} \times M_{m}+e_{i j k l m}
$$

Here, $Y_{i j k l m}$ is the phenotypic value of each milk fatty acid trait; $\mu$ is the overall mean; $G_{i}$ is the fixed effect corresponding to the genotype or haplotype combination; $h_{j}$ is the fixed effect of farm; $l_{k}$ is the stage of lactation; $a_{l}$ is the random polygenic effect; $M_{m}$ is the fixed effect of age at calving; $\mathrm{b}$ is the regression coefficient of covariate $\mathrm{M}$; and $e_{i j k l m}$ is the random residual.

Further, we calculated the additive effect (a), dominant effect (d), and substitution effect $(\alpha)$ of SNP on the milk fatty acid traits according to the formulas [42]: $\mathrm{a}=\frac{A A-B B}{2}, d=A B-\frac{A A+B B}{2}$, and $\alpha=\mathrm{a}+d(q-p)$, in which, $p$ and $q$ were the frequencies of $\mathrm{A}$ and $\mathrm{B}$, respectively; and $\mathrm{AA}, \mathrm{AB}$ and $\mathrm{BB}$ were the least square means of fatty acids corresponding to the genotypes.

\section{Prediction of the secondary structure and function changes of the HTR1B protein}

We used the NPSA SOPMA SERVER program (https://npsa-prabi.ibcp.fr/cgi-bin/npsa_automat.pl? page=npsa_sopma.html) to predict whether the identified missense mutation in coding region changed HTR1B protein secondary structure, and set the parameters with similarity threshold (8), and number of states (4-Helix, Sheet, Turn, Coil). Also, we used the SIFT (http://sift.bii.a-star.edu.sg/) and PROVEAN (http://sift.jcvi.org/index.php) to investigate whether the missense mutation altered the protein function. The score thresholds of the SIFT and PROVEAN were 0.05 [43] and -2.5 [44], respectively. When the score is below the threshold, the protein function is considered changed. 


\section{Prediction of the changes of transcription factor binding sites (TFBSs)}

We predicted whether the SNPs in 5' UTR and flanking region of the HTR1B gene impacted on TFBSs by using the Genomatix suite v3.9 (http://www.genomatix.de/cgi-bin/welcome/welcome.pl?

$s=d 1 b 5 c 9 a 9015 b 02 b b 3 b 1 a 806 f 9 c 03293 f)$.

\section{Construction of recombinant plasmid, cell culture and luciferase assay}

We constructed six luciferase reporter gene fragments with Kpn1 and Nhel restriction sites at the $5^{\prime}$ to $3^{\prime}$ termini (Figure 3), which contained alleles $A$ and $T$ of g.17307103A $>T$, $T$ and $G$ of g.17305206T $>G$, and $C$ and $T$ of g.17303761C>T. The six fragments were synthesized in Genewiz (Suzhou, China), and were cloned into the pGL4.14 Luciferase Assay Vector (Promega, Madison, USA). Subsequently, the plasmids were purified by Endo-free Plasmid DNA Mini Kit $\otimes($ OMEGA, omega bio-tek, Norcross, Georgia, USA), and then were sequenced to confirm the integrity of each construct's insertions.

Human Embryonic Kidney (HEK)-293T cells were cultured in Dulbecco's modified Eagle's medium (DMEM) including $10 \%$ heat-inactivated fetal bovine serum (FBS; Gibco, Life Technologies) at $5 \% \mathrm{CO}_{2}$ and $37^{\circ} \mathrm{C}$. We seeded approximately $2 \times 10^{5}$ cells per well into 24 -well plates, and transfected the cells using Lipofectamine 2000 (Invitrogen, CA, USA). For each well, we transfected 500ng of the constructed plasmid DNA along with 10ng of pRLTK renilla luciferase reporter vector (Promega), and conducted three replicates for each construct. The cells were cultured for about 36-48h after transfection and then were measured the activities of firefly and renilla luciferases using a Dual-Luciferase Reporter Assay System (Promega) with a Modulus microplate multimode reader (Turner Biosystems, CA, USA). Finally, average statistics of three replicates were calculated as the normalized luciferase data (firefly/renilla).

\section{List Of Abbreviations}

a: Additive effect; d: Dominant effect; FA: Fatty acids; GWAS: Genome-wide association study; HTR1B: 5hydroxytryptamine receptor 1B; LD: Linkage disequilibrium; PCR: Polymerase chain reaction; SFA: Saturated fatty acids; SNP: Single nucleotide polymorphism; TF: Transcription factor; TFBS: Transcription factor binding site; UFA: Unsaturated fatty acids; UTR: Untranslated region; a: Substitution effect.

\section{Declarations}

\section{Ethics approval and consent to participate}

All protocols for collection of the samples of experimental individuals and phenotypic observations were reviewed and approved by the Institutional Animal Care and Use Committee (IACUC) at China Agricultural University (Permit Number: DK996). Blood, semen and milk samples were collected specifically for this study following standard procedures with the full agreement of the Beijing Sanyuanlvhe Dairy Farming Center who owned the Holstein cows and bulls, respectively.

\section{Consent for publication}

Not applicable. 
All data generated or analysed during this study are included in this published article and its supplementary information files.

\section{Competing interests}

The authors declare that they have no competing interests.

\section{Funding}

This research was funded by the Beijing Science and Technology Program (20200105, D171100002417001)区 National Science and Technology Programs of China (2013AA102504), National Natural Science Foundation of China (31872330, 31802041), earmarked fund for Modern Agro-industry Technology Research System (CARS-36), and the Program for Changjiang Scholar and Innovation Research Team in University (IRT_15R62). These funding bodies had no roles in the design of the study and collection, analysis, and interpretation of data and in writing the manuscript.

\section{Authors' contributions}

DS and SZ conceived and designed the experiments, $L L, X L$ and ZM prepared the milk, blood and semen samples, PP measured the milk fatty acids, MC and LS extracted the DNA for SNP identification and genotyping with the help of $\mathrm{BH}, \mathrm{MC}$ analyzed the data, and the manuscript was prepared by MC, LS, SZ and DS. All authors read and approved the final manuscript.

\section{Acknowledgements}

We appreciate Beijing Dairy Cattle Center, Beijing Municipal Bureau of Agriculture, and Beijing Sanyuanlvhe Dairy Farming Center, for providing the milk, semen, and blood samples of Chinese Holstein.

\section{References}

1. Spelman RJ, Coppieters W, Karim L, van Arendonk JA, Bovenhuis H: Quantitative trait loci analysis for five milk production traits on chromosome six in the Dutch Holstein-Friesian population. Genetics 1996, 144(4):17991808.

2. Pennington RJ: The metabolism of short-chain fatty acids in the sheep. I. Fatty acid utilization and ketone body production by rumen epithelium and other tissues. Biochem J 1952, 51(2):251-258.

3. Lordan R, Tsoupras A, Mitra B, Zabetakis I: Dairy Fats and Cardiovascular Disease: Do We Really Need to be Concerned? Foods 2018, 7(3).

4. Yu E, Hu FB: Dairy Products, Dairy Fatty Acids, and the Prevention of Cardiometabolic Disease: a Review of Recent Evidence. Current atherosclerosis reports 2018, 20(5):24.

5. Assmann KE, Adjibade M, Hercberg S, Galan P, Kesse-Guyot E: Unsaturated Fatty Acid Intakes During Midlife Are Positively Associated with Later Cognitive Function in Older Adults with Modulating Effects of Antioxidant Supplementation. J Nutr 2018, 148(12):1938-1945.

6. Kris-Etherton PM, Pearson TA, Wan Y, Hargrove RL, Moriarty K, Fishell V, Etherton T: High-monounsaturated fatty acid diets lower both plasma cholesterol and triacylglycerol concentrations. Am J Clin Nutr 1999, 70(6):10091015. 
7. Narayana SG, Schenkel FS, Fleming A, Koeck A, Malchiodi F, Jamrozik J, Johnston J, Sargolzaei M, Miglior F: Genetic analysis of groups of mid-infrared predicted fatty acids in milk. Journal of dairy science 2017, 100(6):4731-4744.

8. Petrini J, lung LH, Rodriguez MA, Salvian M, Pertille F, Rovadoscki GA, Cassoli LD, Coutinho LL, Machado PF, Wiggans GR et al: Genetic parameters for milk fatty acids, milk yield and quality traits of a Holstein cattle population reared under tropical conditions. Journal of animal breeding and genetics = Zeitschrift fur Tierzuchtung und Zuchtungsbiologie 2016, 133(5):384-395.

9. Krag K, Poulsen NA, Larsen MK, Larsen LB, Janss LL, Buitenhuis B: Genetic parameters for milk fatty acids in Danish Holstein cattle based on SNP markers using a Bayesian approach. Bmc Genet 2013, 14:79.

10. Stoop WM, Schennink A, Visker MH, Mullaart E, van Arendonk JA, Bovenhuis H: Genome-wide scan for bovine milk-fat composition. I. Quantitative trait loci for short- and medium-chain fatty acids. Journal of dairy science 2009, 92(9):4664-4675.

11. Schennink A, Stoop WM, Visker MH, van der Poel JJ, Bovenhuis H, van Arendonk JA: Short communication: Genome-wide scan for bovine milk-fat composition. II. Quantitative trait loci for long-chain fatty acids. Journal of dairy science 2009, 92(9):4676-4682.

12. Li C, Sun DX, Zhang SL, Wang S, Wu XP, Zhang Q, Liu L, Li YH, Qiao L: Genome Wide Association Study Identifies 20 Novel Promising Genes Associated with Milk Fatty Acid Traits in Chinese Holstein. Plos One 2014, 9(5).

13. Fan Y, He Z, Wang W, Li J, Hu A, Li L, Yan L, Li Z, Yin Q: Tangganjian decoction ameliorates type 2 diabetes mellitus and nonalcoholic fatty liver disease in rats by activating the IRS/PI3K/AKT signaling pathway. Biomed Pharmacother 2018, 106:733-737.

14. Bettella F, Rasinski D, Knapp EW: Protein secondary structure prediction with SPARROW. Journal of chemical information and modeling 2012, 52(2):545-556.

15. Colubri A: Prediction of protein structure by simulating coarse-grained folding pathways: a preliminary report. Journal of biomolecular structure \& dynamics 2004, 21(5):625-638.

16. Rost B, Schneider R, Sander C: Protein fold recognition by prediction-based threading. Journal of molecular biology 1997, 270(3):471-480.

17. Fischer D, Eisenberg D: Protein fold recognition using sequence-derived predictions. Protein science : a publication of the Protein Society 1996, 5(5):947-955.

18. Baker D, Sali A: Protein structure prediction and structural genomics. Science 2001, 294(5540):93-96.

19. Thornton JM, Orengo CA, Todd AE, Pearl FM: Protein folds, functions and evolution. Journal of molecular biology 1999, 293(2):333-342.

20. Pal C, Papp B, Lercher MJ: An integrated view of protein evolution. Nature reviews Genetics 2006, 7(5):337-348.

21. Cheng YJ, Yao H, Ji CC, Chen XM, Fan J, Liu LJ, Wu SH: A Heterozygous Missense hERG Mutation Associated with Early Repolarization Syndrome. Cell Physiol Biochem 2018, 51(3):1301-1312.

22. Nakayama M, Oshima M: Mutant p53 in colon cancer. Journal of molecular cell biology 2018.

23. Guedes LB, Almutairi F, Haffner MC, Rajoria G, Liu Z, Klimek S, Zoino R, Yousefi K, Sharma R, De Marzo AM et al: Analytic, Preanalytic, and Clinical Validation of p53 IHC for Detection of TP53 Missense Mutation in Prostate Cancer. Clinical cancer research : an official journal of the American Association for Cancer Research 2017, 23(16):4693-4703.

24. Li LX, Dong HL, Xiao BG, Wu ZY: A Novel Missense Mutation in Peripheral Myelin Protein-22 Causes CharcotMarie-Tooth Disease. Chin Med J (Engl) 2017, 130(15):1779-1784. 
25. Singh AP, Mishra S, Jabin S: Sequence based prediction of enhancer regions from DNA random walk. Sci Rep 2018, 8(1):15912.

26. Plank JL, Dean A: Enhancer function: mechanistic and genome-wide insights come together. Molecular cell 2014, 55(1):5-14.

27. Lelli KM, Slattery M, Mann RS: Disentangling the many layers of eukaryotic transcriptional regulation. Annual review of genetics 2012, 46:43-68.

28. Lambert SA, Jolma A, Campitelli LF, Das PK, Yin Y, Albu M, Chen X, Taipale J, Hughes TR, Weirauch MT: The Human Transcription Factors. Cel/2018, 175(2):598-599.

29. Bouhlel MA, Lambert M, David-Cordonnier MH: Targeting Transcription Factor Binding to DNA by Competing with DNA Binders as an Approach for Controlling Gene Expression. Current topics in medicinal chemistry 2015, 15(14):1323-1358.

30. Chen H, Li H, Liu F, Zheng X, Wang S, Bo X, Shu W: An integrative analysis of TFBS-clustered regions reveals new transcriptional regulation models on the accessible chromatin landscape. Sci Rep 2015, 5:8465.

31. Adamska M, Wolff A, Kreusler M, Wittbrodt J, Braun T, Bober E: Five Nkx5 genes show differential expression patterns in anlagen of sensory organs in medaka: insight into the evolution of the gene family. Development genes and evolution 2001, 211(7):338-349.

32. Stadler HS, Murray JC, Leysens NJ, Goodfellow PJ, Solursh M: Phylogenetic conservation and physical mapping of members of the $\mathrm{H} 6$ homeobox gene family. Mammalian genome : official journal of the International Mammalian Genome Society 1995, 6(6):383-388.

33. Jiang Y, Horner V, Liu J: The HMX homeodomain protein MLS-2 regulates cleavage orientation, cell proliferation and cell fate specification in the C. elegans postembryonic mesoderm. Development 2005, 132(18):4119-4130.

34. Kiernan AE, Nunes F, Wu DK, Fekete DM: The expression domain of two related homeobox genes defines a compartment in the chicken inner ear that may be involved in semicircular canal formation. Developmental biology 1997, 191(2):215-229.

35. Wang W, Lufkin T: Hmx homeobox gene function in inner ear and nervous system cell-type specification and development. Exp Cell Res 2005, 306(2):373-379.

36. Maroon H, Walshe J, Mahmood R, Kiefer P, Dickson C, Mason I: Fgf3 and Fgf8 are required together for formation of the otic placode and vesicle. Development 2002, 129(9):2099-2108.

37. Feng $\mathrm{Y}, \mathrm{Xu} \mathrm{Q}$ : Pivotal role of $\mathrm{hmx2}$ and $\mathrm{hmx3}$ in zebrafish inner ear and lateral line development. Developmental biology 2010, 339(2):507-518.

38. Grimley E, Liao C, Ranghini EJ, Nikolovska-Coleska Z, Dressler GR: Inhibition of Pax2 Transcription Activation with a Small Molecule that Targets the DNA Binding Domain. ACS chemical biology 2017, 12(3):724-734.

39. Doberstein K, Pfeilschifter J, Gutwein P: The transcription factor PAX2 regulates ADAM10 expression in renal cell carcinoma. Carcinogenesis 2011, 32(11):1713-1723.

40. Shi L, Liu L, Ma Z, Lv X, Li C, Xu L, Han B, Li Y, Zhao F, Yang Y et al: Identification of genetic associations of ECHS1 gene with milk fatty acid traits in dairy cattle. Anim Genet 2019, 50(5):430-438.

41. Kelsey JA, Corl BA, Collier RJ, Bauman DE: The effect of breed, parity, and stage of lactation on conjugated linoleic acid (CLA) in milk fat from dairy cows. Journal of dairy science 2003, 86(8):2588-2597.

42. Falconer DS, Mackay TFC: Introduction to quantitative genetics. 1996: Ed. 4 xv + 464 pp.

43. Kumar P, Henikoff S, Ng PC: Predicting the effects of coding non-synonymous variants on protein function using the SIFT algorithm. Nature protocols 2009, 4(7):1073-1081. 
44. Choi Y, Sims GE, Murphy S, Miller JR, Chan AP: Predicting the functional effect of amino acid substitutions and indels. Plos One 2012, 7(10):e46688.

\section{Figures}

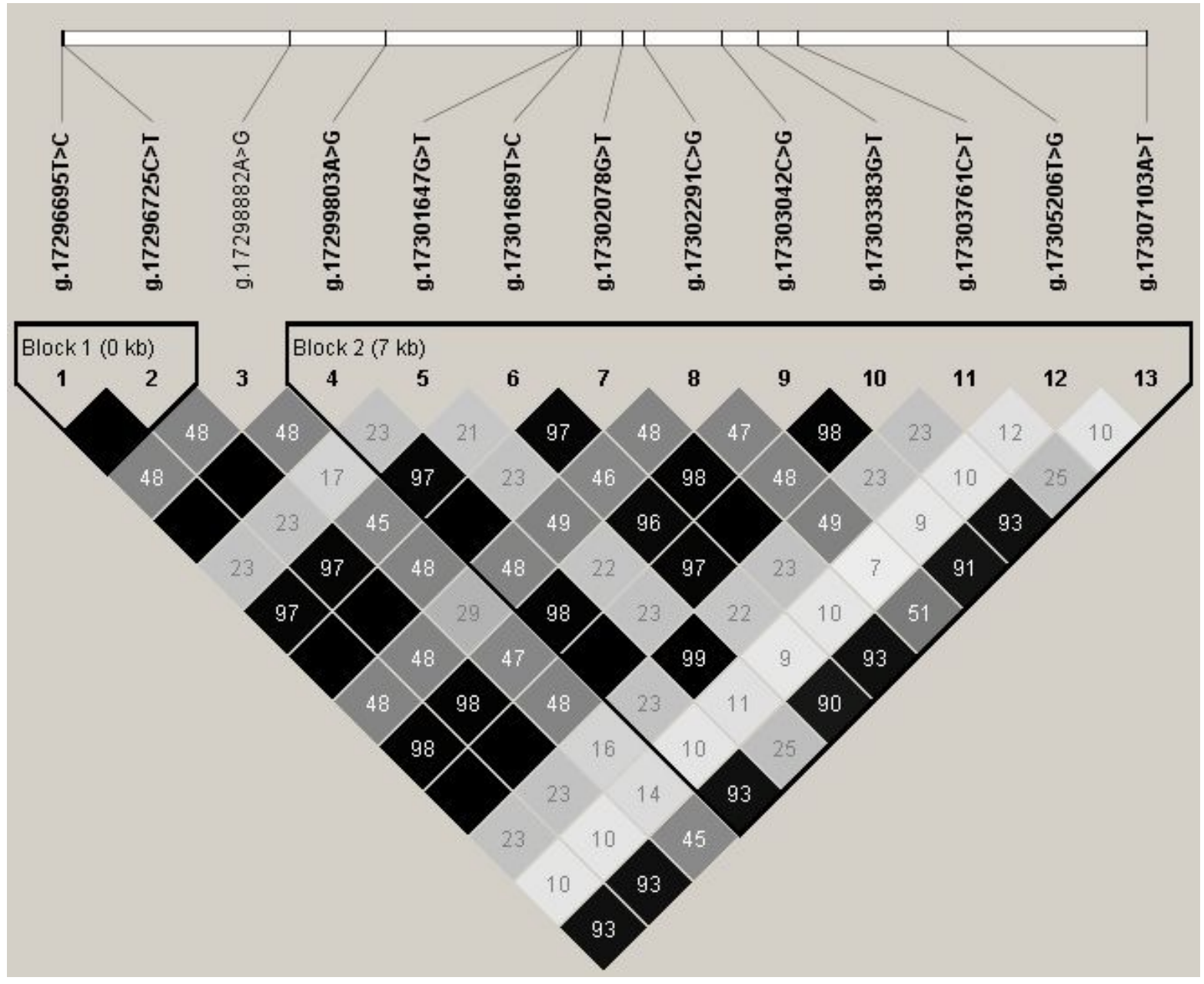

Figure 1

Linkage disequilibrium (LD) among the 13 SNPs of HTR1B gene 


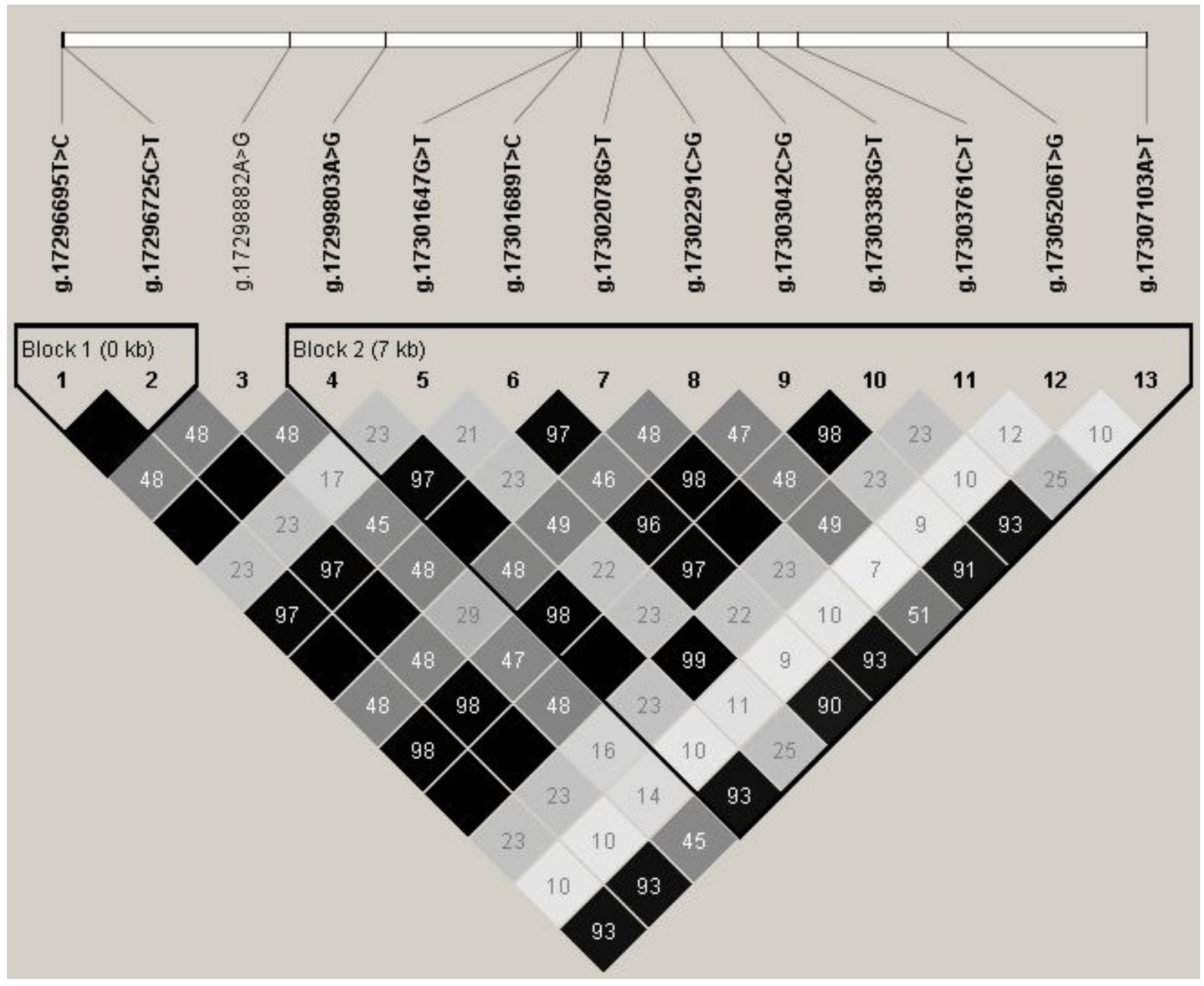

Figure 1

Linkage disequilibrium (LD) among the 13 SNPs of HTR1B gene 

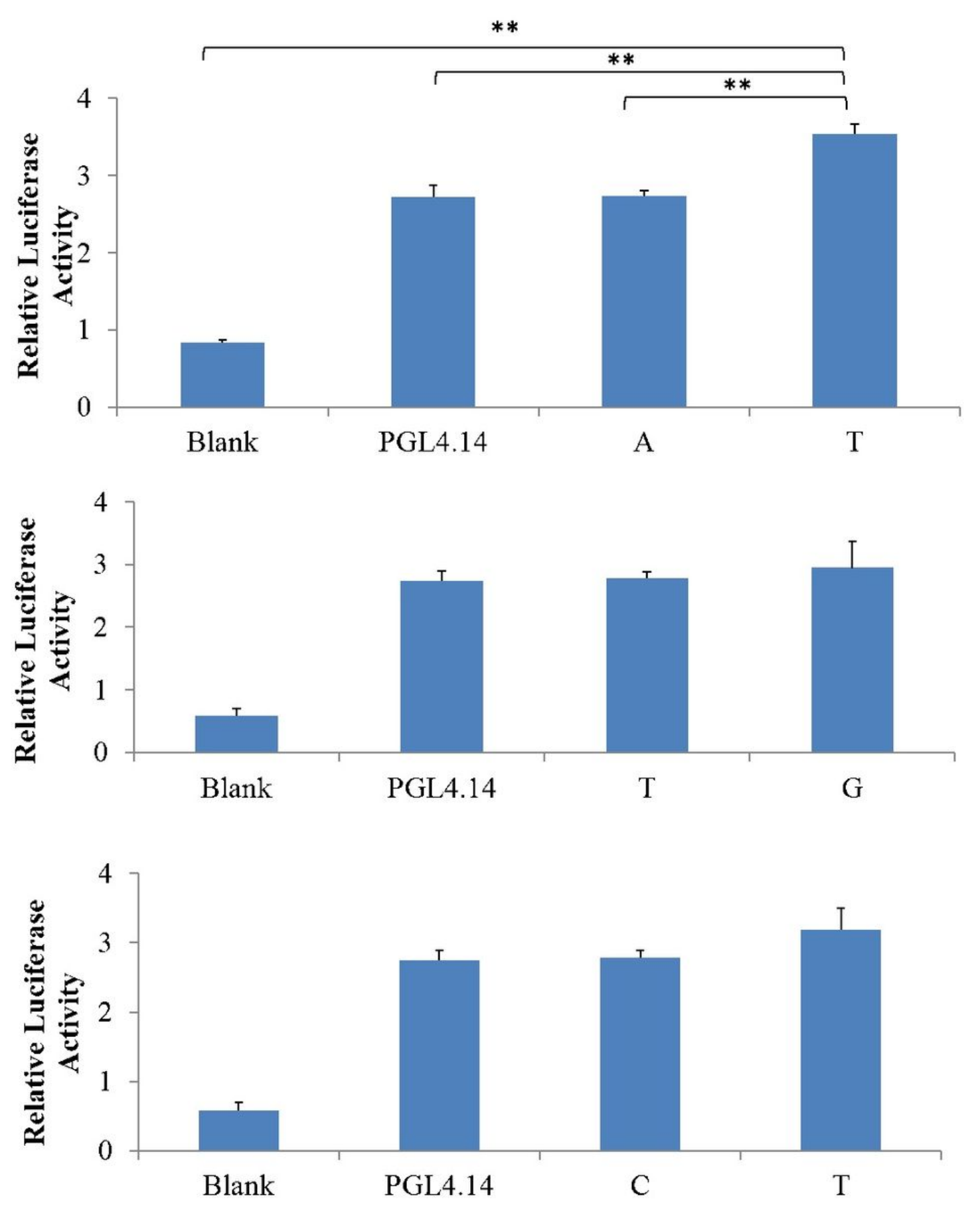

Figure 2

Luciferase assay analysis of the recombinant plasmids in HEK293 cells. Blank: Blank cells. PGL4.14: Empty vector. A and T: Plasmids of g.17307103A>T. T and G: Plasmids of g.17305206T >G. C and T: Plasmids of g.17303761C>T. **: $P<0.01$ 

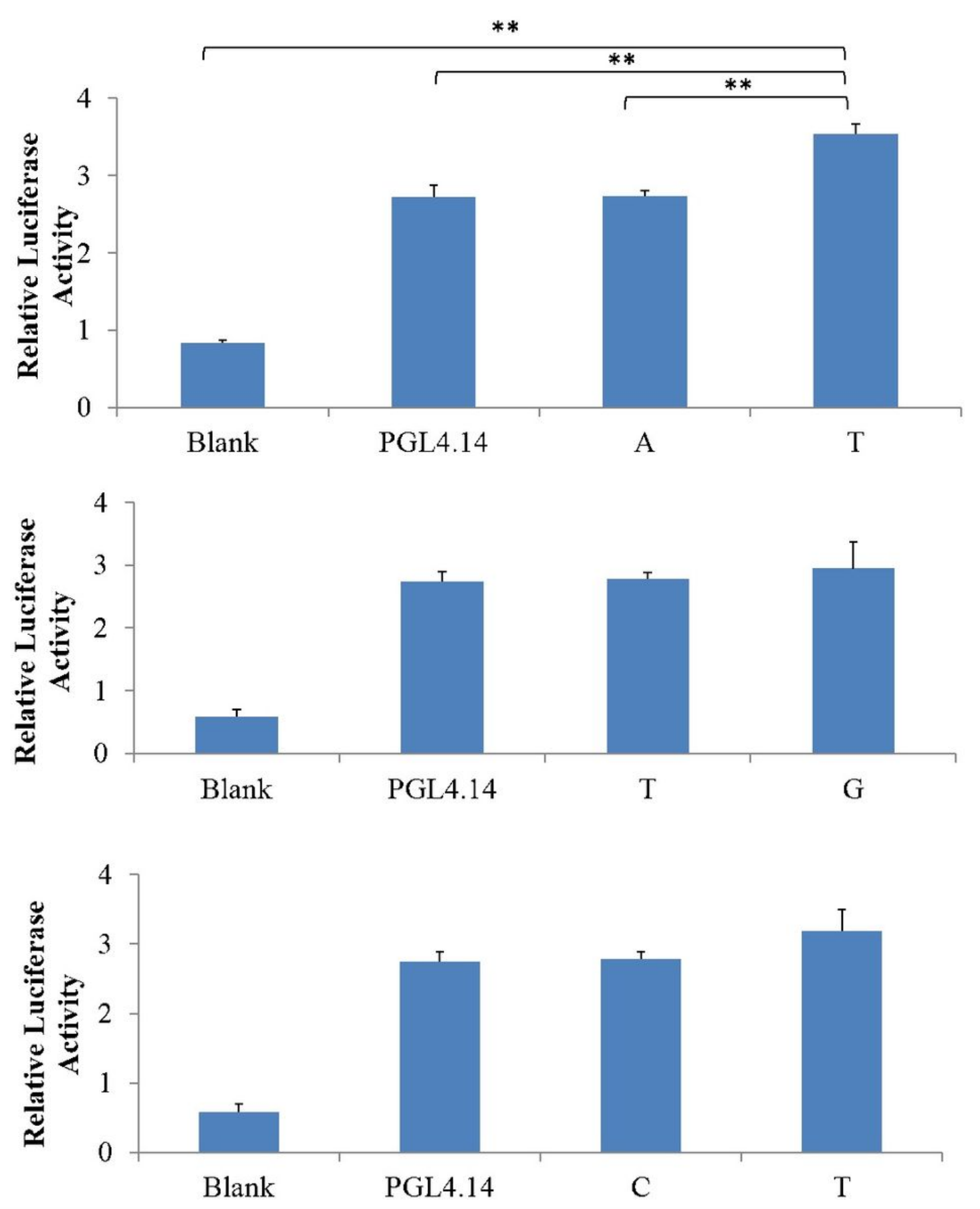

Figure 2

Luciferase assay analysis of the recombinant plasmids in HEK293 cells. Blank: Blank cells. PGL4.14: Empty vector. A and T: Plasmids of g.17307103A>T. T and G: Plasmids of g.17305206T >G. C and T: Plasmids of g.17303761C>T. **: $P<0.01$ 
5'-CCCCAACGCGATTCCCTCCTT-3'

g. $17307103 \mathrm{~A}>\mathrm{T}$ (A)

A HTR1B 5' flanking region $\quad$ luciferase

5'-CCCCAACGCGTTTCCCTCCTT-3'

g. $17307103 \mathrm{~A}>\mathrm{T}(\mathrm{T})$

$\mathrm{T}$ HTRIB $5^{\prime}$ flanking region luciferase

5'-TTTTGAAGTTTTTTTTTTTTTT-3'

g. $17305206 \mathrm{~T}>\mathrm{G}(\mathrm{T})$

$\mathrm{T}$ HTRlB 5' UTR $\quad$ luciferase

5'-TTTTGAAGTTTGTTTTTTTTTT-3'

g. $17305,206 \mathrm{~T}>\mathrm{G}(\mathrm{G})$

$\mathrm{G}$ HTRlB 5' UTR

5'-ACCTCGCCCTCGACCTCTCGC-3'

g. $17303761 \mathrm{C}>\mathrm{T}(\mathrm{C})$

$\mathrm{C} \longrightarrow$ HTRIB 5' UTR Luciferase

5'-ACCTCGCCCTTGACCTCTCGC-3'

g. $17303761 \mathrm{C}>\mathrm{T}(\mathrm{T})$

$\mathrm{T} \longrightarrow$ HTRIB 5' UTR Luciferase

Figure 3

Sketches of recombinant plasmids. The nucleotides in red highlight referred to the SNP 
5'-CCCCAACGCGATTCCCTCCTT-3'

(

g. $17307103 \mathrm{~A}>\mathrm{T}(\mathrm{A})$

A HTRIB 5' flanking region $\quad$ luciferase

5'-CCCCAACGCGTTTCCCTCCTT-3'

g. $17307103 \mathrm{~A}>\mathrm{T}(\mathrm{T})$

$\mathrm{T}$ HTRIB 5' flanking region luciferase

5'-TTTTGAAGTTTTTTTTTTTTTT-3'

g. 17305 206T $>\mathrm{G}(\mathrm{T})$

$\mathrm{T}$ HTRlB 5' UTR $\quad$ luciferase

5'-TTTTGAAGTTTGTTTTTTTTTT-3'

g. 17305 206T $>\mathrm{G}(\mathrm{G})$

$\mathrm{G}$ HTRlB 5' UTR

5'-ACCTCGCCCTCGACCTCTCGC-3'

g. $17303761 \mathrm{C}>\mathrm{T}(\mathrm{C})$

C

HTRIB 5' UTR

luciferase

5'-ACCTCGCCCTTGACCTCTCGC-3'

g. $17303761 \mathrm{C}>\mathrm{T}(\mathrm{T})$

$\mathrm{T}$

HTR IB 5' UTR

luciferase

Figure 3

Sketches of recombinant plasmids. The nucleotides in red highlight referred to the SNP

\section{Supplementary Files}

This is a list of supplementary files associated with this preprint. Click to download.

- Tables1.xls

- Tables1.xls

- Tables2.xls 
- Tables2.xls

- Tables3.xls

- Tables3.xls

- Tables4.xls

- Tables4.xls 